\title{
Propuesta metodológica, principios teóricos y enfoques para el proceso de creación dramatúrgica actoral
}

Proposta metodológica, princípios teóricos e enfoques para o processo de criação dramatúrgica atorial

\author{
Methodological proposal, theoretical principles \\ and approaches for the atomic dramaturgical \\ creation process
}

Elisa Martins Lucas

Atriz, dramaturga, pesquisadora, oficineira de teatro e diretora de Artes Cênicas no Instituto de Artes da UFRGS. Fundadora do Grupo Capitu - Teatro e Pesquisa Cênica. Instituição: Instituto de Artes da Universidade Federal do Rio Grande do Sul E-mail: elisa.lucas97@gmail.com ORCID: https://orcid.org/0000-0003-2569-4873

\section{RESUMEN:}

El artículo presenta una propuesta metodológica para el proceso de creación dramatúrgica actoral, que es una fusión de distintas metodologías de práctica escénica, teniendo por base el trabajo práctico de una actriz/dramaturga, apoyándose en postulados teóricos del arte de actor/actriz y en procedimientos de creadores contemporáneos. Tal propuesta, resultado de una investigación cuya metodología presentó características de una investigación práctica en las artes, puede proporcionar a profesionales y estudiantes de las Artes Escénicas instrumentalización para dar voz a sus creaciones y autonomía en sus procesos.

LUCAS, Elisa Martins. Propuesta metodológica, principios teóricos y enfoques para el proceso de creación dramatúrgica actoral.

PÓS:Revista do Programa de Pós-graduação em Artes da EBA/UFMG. v.10, n.19: mai.2020

Disponível em < $\underline{\text { https://eba.ufmg.br/revistapos }}>$ 
Palabras-clave: Proceso de creación dramatúrgica actoral. Interpretación Teatral. Dramaturgia.

\section{RESUMO:}

O artigo apresenta uma proposta metodológica para o processo de criação dramatúrgica atorial, que é uma fusão de distintas metodologias de prática cênica, tendo como base o trabalho prático de uma atriz/dramaturga, apoiando-se em postulados teóricos da arte de ator/atriz e em procedimentos de criadores(as) contemporâneos(as). Tal proposta, resultado de uma pesquisa cuja metodologia apresentou características de uma pesquisa prática nas artes, pode proporcionar a profissionais e estudantes das Artes Cênicas instrumentalização para dar voz a suas criações e autonomia em seus processos.

Palavras-chave: Processo de criação dramatúrgica atorial. Interpretação Teatral. Dramaturgia.

\section{ABSTRACT:}

The article presents a methodological proposal for the atorial dramaturgical creation process, which is a fusion of different scenic practice methodologies, based on the practical work of an actress/dramaturge, relying on theoretical postulates of the actor/actress art and on procedures of contemporary creators. This proposal, the result of a research whose methodology presented characteristics of a practical research in the arts, can provide professionals and students of the Performing Arts instrumentalization to give voice to their creations and autonomy in their processes.

Keywords: Atorial dramaturgical creation process. Theatrical Interpretation. Dramaturgy.

Artigo recebido em: 09/09/2019

Artigo aprovado em: 31/01/2020

LUCAS, Elisa Martins. Propuesta metodológica, principios teóricos y enfoques para el proceso de creación dramatúrgica actoral.

PÓS:Revista do Programa de Pós-graduação em Artes da EBA/UFMG. v.10, n.19: mai.2020

Disponível em $<\underline{\text { https://eba.ufmg.br/revistapos }>}$

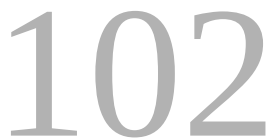




\section{Introducción}

El proceso de creación dramatúrgica actoral consiste en prácticas donde el/la actor/actriz, ${ }^{1}$ trabajando de forma práctica y artesanal, actúa también como autor(a), interfiriendo en la elaboración textual de la obra (LUCAS, 2016). En el panorama teatral, las creaciones del Odin Teatret (Dinamarca), del Théâtre du Soleil (Francia), del Grupo Lume - Núcleo Interdisciplinar de Pesquisas Teatrais da Unicamp y de la Tribo de Atuadores Ói Nóis Aqui Traveiz (Brasil), así como los textos de Dario Fo (Italia), cada uno con sus particularidades, podrían ser considerados ejemplos de procesos de creación dramatúrgica actorales, una vez que el/la actor/actriz posee cierta autonomía en la creación dramatúrgica.

Con el objeto de sistematizar una metodología para el proceso de creación dramatúrgica actoral, una actriz/dramaturga, que es la autora de este estudio, en colaboración con un equipo de expertos, desarrolló un experimento del proceso que diseñó una dramaturgia de nueva creación y puesta en escena en torno a María Madalena, personaje consagrado por la literatura y por el imaginario popular. El experimento formó parte de la investigación para la tesis Lo Profano y lo Sagrado en el proceso de creación dramatúrgica del actor a partir del personaje de María Magdalena. Interrelación entre Teoría y Praxis Escénica (2016) realizada en el Doctorado en Ciencias del Espectáculo de la Universidad de Sevilla, dirigida por la Profesora Doctora María Concepción Pérez, con Beca de la Coordinación de Perfeccionamiento de Personal de Nivel Superior (CAPES-Brasil).

La metodología adoptada en la tesis presentó características de una investigación práctica en las artes, según Borgdorff (2010), Pérez y Sánchez (2010) y Sánchez (2009), pesquisa orientada al conocimiento plasmado en las prácticas artísticas (objetos y procesos), cuyo diseño reúne "(...) experimentación y participación en la práctica y la interpretación de esta práctica" (BORGDORFF, 2010, p. 26). Tal metodología incluye el artista en el campo del saber, no separa el sujeto del objeto de estudio de igual modo que no separa práctica y teoría, siendo su componente primordial la experimentación práctica.

LUCAS, Elisa Martins. Propuesta metodológica, principios teóricos y enfoques para el proceso de creación dramatúrgica actoral.

PÓS:Revista do Programa de Pós-graduação em Artes da EBA/UFMG. v.10, n.19: mai.2020

Disponível em < $\underline{\text { https://eba.ufmg.br/revistapos }}>$

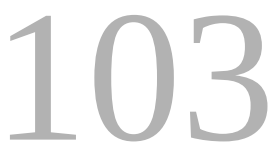


Este artículo presenta una propuesta metodológica para el proceso de creación dramatúrgica actoral, objetivo final de la investigación, estructurada con base en los estudios prácticos realizados y presupuestos teóricos consultados. Tal propuesta es una fusión de distintas metodologías de práctica escénica, teniendo como base el trabajo práctico de una actriz/dramaturga, apoyándose en postulados teóricos del arte de actor/actriz y en procesos de creación escénica y dramatúrgica contemporáneas, incluyendo obras de Barba (1986, 2010), Carreri (1990), Ferracini (2001), Grotowski (1976), Oida (2001), Pavis (2003), entre otros(as). Se utilizaron además estudios, entrevistas, vídeos y demostraciones de trabajo de creadores(as) contemporáneos(as). En ella, se contempla la posibilidad del actor/actriz ser dueño(a) de su trabajo: tomando parte activa en la creación, artesanalmente, de forma que la dramaturgia se construya por medio de improvisaciones y acciones físicas y vocales, habiendo elegido libremente un tema cualquiera, ya sea un personaje de una novela, relato, biografía, o una idea a partir de la cual se pueda crear un texto/obra teatral. El/la intérprete, mediante improvisaciones corpóreo-vocales, añadirá matices a la idea que le ha servido de base. La propuesta se divide en dos partes complementarias cuyos principios teóricos y enfoques son presentados en detalles a continuación.

\section{Primera parte de la propuesta metodológica: El trabajo del actor/ actriz como intérprete}

La primera parte de la propuesta metodológica enfoca el trabajo del actor/actriz como intérprete, proponiendo la sistematización de la interpretación a partir del entrenamiento - en la acepción de Jerzy Grotowski y Eugenio Barba, refiriéndose al trabajo práctico actoral anterior a la actuación - y del trabajo con las acciones y la voz.

\subsection{El entrenamiento actoral como trampolín para la interpretación}

Para crear en el teatro hay que aprender a reaccionar y hacerlo de una forma más visible de lo que se suele hacer en el cotidiano. El/la actor/actriz busca nuevas formas de actuar y reaccionar para lograr una tensión dramática a nivel físico. El plano psicológico es más difícil de mostrar frente a un

LUCAS, Elisa Martins. Propuesta metodológica, principios teóricos y enfoques para el proceso de creación dramatúrgica actoral.

PÓS:Revista do Programa de Pós-graduação em Artes da EBA/UFMG. v.10, n.19: mai.2020

Disponível em < $\underline{\text { https://eba.ufmg.br/revistapos }>}$

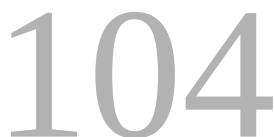


público, por lo que el cuerpo suple esa carencia mediante una preparación adecuada, también llamada de entrenamiento actoral, que actúa como base del trabajo del actor/actriz. El entrenamiento potencializa las acciones físicas, vocales y la capacidad de imaginación del intérprete, confiriéndole autonomía en la escena. Realizado de forma técnica, permite que el cuerpo/mente del actor/actriz reaccione de manera fluida y orgánica. Mediante la constancia, el/la intérprete supera sus límites, a medida que conoce más de su todo psicofísico. Para Grotowski (1976, p. 204), el cuerpo, material de trabajo del actor/actriz debe ser adiestrado para obedecer a la mente, ser flexible y responder pasivamente a los impulsos psíquicos sin resistencia. Cuando el cuerpo no ofrece resistencia, existe la posibilidad de la impulsión interior, y el/la intérprete logra expresar los impulsos que habitan la frontera entre sueño y realidad por medio de sonidos y movimientos (GROTOWSKI, 1976, p. 20).

Según Barba (1986, p. 74-75), el objetivo del entrenamiento actoral es hacer que todo el cuerpo actúe y reaccione, pudiendo adaptarse con la máxima precisión a cualquier situación que pueda surgir en el escenario. Carreri (1990, p. 41) añade que: "El entrenamiento es el tiempo y el espacio en que el actor trabaja para construir su presencia y romper esquemas automáticos y mecanismos de relación (los clichés)".

Las técnicas utilizadas en entrenamientos actorales son de tipo muy diverso y a veces, de naturaleza efímera. Si en un momento funcionan y ayudan al actor/actriz a conseguir determinado objetivo, en otro momento dejan de funcionar y habrán de ser sustituidas. Como indica Carreri (1990, p. 43): "Se había vuelto una cosa del todo automática. Mi cuerpo trabajaba por sí; el training me llevaba, en vez de ser yo a dirigir el training (...) necesitaba de una nueva dirección". Igualmente, no todas las técnicas funcionan igual para todos los(as) actores/actrices. El/la intérprete debe estar atento(a), de forma que perciba lo que funciona y lo que no, y vaya descubriendo las técnicas que más le ayudan a comunicarse con su público, basando su preparación en procedimientos concretos, que serán experimentados prácticamente y que irán evolucionando a lo largo de su trayectoria artística. Igualmente debe tener en cuenta que no basta dominar recursos técnicos, sino que hay que llegar a lo humano y a lo imaginario. De nada sirve entrenar a ritmo frenético o dominar múltiples técnicas, si no se logra la comunicación con el público. Oida (2001, p. 22) indica

LUCAS, Elisa Martins. Propuesta metodológica, principios teóricos y enfoques para el proceso de creación dramatúrgica actoral.

PÓS:Revista do Programa de Pós-graduação em Artes da EBA/UFMG. v.10, n.19: mai.2020 Disponível em < $\underline{\text { https://eba.ufmg.br/revistapos }>}$

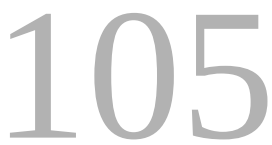


que el trabajo actoral no es ostentar habilidad técnica, sino dar vida al escenario. Barba, en la en la residencia de creación y montaje El Arte Secreto del Actor - Brasil, ${ }^{2}$ añade que el trabajo actoral consiste en no convertirse en un(a) experto(a) para que se pueda incorporar cualquier cosa.

Al tiempo que se instrumentaliza físicamente, el/la actor/actriz debe mantener alerta su imaginación, de modo que pueda dar vida, no solamente a las diferentes partes del cuerpo que entran en acción, sino también a las imágenes y sentimientos accionados durante el entrenamiento. Así, además de trabajar la presencia escénica e impedir bloqueos corporales, el/la intérprete se hará más proclive a los matices en la interpretación. Jean-Jacques Lemêtre, en su taller El Cuerpo Musical en el Teatro, ${ }^{3}$ utiliza la expresión 'sencillez sin artificios' y habla de la unión de la precisión, consciencia y presencia que dan al actor/actriz la capacidad de dar cuerpo a lo poético, al sueño.

Si el/la intérprete no se comunica con el propio cuerpo, el cuerpo hace lo que quiere, y el/la intérprete no se comunica con su público. Para que se dé esa comunicación, el/la actor/actriz debe procurar que sus acciones posean principio, medio y fin, prestando suma atención a su cuerpo/ mente. Es decir, ya que el instrumento del actor/actriz es su todo psicofísico, la única forma de desempeñar dignamente el oficio es entrenándose y poniéndose a punto para el trabajo. La preparación que realiza el/la actor/actriz consiste en la unión de técnica y creación, precisión y sensibilidad, sistematización y artesanía. Esta preparación puede empezar mediante un calentamiento corporal que facilite la movilización de articulaciones, así como el estiramiento de la columna vertebral. La finalidad que se persigue es que el cuerpo reaccione con precisión y agudeza. Luego, el/la actor/actriz introduce movimientos acrobáticos, pasos de baile, Capoeira, Ballet $\mathrm{u}$ otro ejercicio que ponga su cuerpo en prontitud.

Mientras realizaba la investigación para la tesis doctoral, la actriz/dramaturga desarrolló una labor de entrenamiento basado en las faenas del gaúcho, variando energía, ritmo, impulsos y respiración. Dicho sistema de entrenamiento fue creado en la investigación As técnicas corporais do gaúcho e sua relação com a performance do ator/dançarino, ${ }^{4}$ dirigida por la Profesora Doctora Inés Marocco, con quien la autora pudo colaborar. Consta de nueve series de movimiento que reproducen las acciones que realiza el gaúcho en el campo: enlazar, prender al animal para abatirlo, domar,

LUCAS, Elisa Martins. Propuesta metodológica, principios teóricos y enfoques para el proceso de creación dramatúrgica actoral.

PÓS:Revista do Programa de Pós-graduação em Artes da EBA/UFMG. v.10, n.19: mai.2020 Disponível em < $\underline{\text { https://eba.ufmg.br/revistapos }>}$

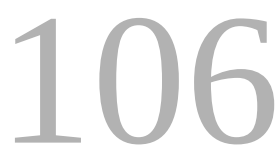


ordeñar, hacer chorizo, jinetear, sacar leche de la vaca, esquilar la oveja y pealar (actividad en extinción en los días actuales, que consiste en enlazar el animal por las patas). Esas secuencias contemplan las leyes del movimiento según el Sistema Pedagógico de Jacques Lecoq (Francia): equilibrio, desequilibrio, alternancia de peso, acción y reacción, oposición y compensación (LECOQ, 1987). Son actividades realizadas normalmente en contacto directo con el animal, lo que requiere prontitud, agilidad y economía de movimientos, debido al riesgo de provocar una reacción brusca del animal. Según Marocco et al (2002), dichos factores desarrollan en el gaúcho precisión, vigor, energía y eficacia, aspectos relacionados por maestros como Meyerhold, Étienne Decroux, Jacques Lecoq y Eugenio Barba con la presencia física del actor/actriz.

\subsection{Acción física: Herramienta para el/la actor/actriz salir del psicologismo}

A continuación, el/la actor/actriz empieza el trabajo con las acciones físicas. Una acción, considerada por Stanislávski como principio impar del arte actoral (TOPORKOV, 2019, p. 92), ejecutada con vigor, de forma directa y a gran velocidad puede provocar en el/la intérprete una emoción o intención de rabia que es perceptible tanto por el/la intérprete como por el/la espectador(a). Cuanto más las emociones son transformadas en acciones o actitudes físicas, más se liberará el/la actor/ actriz de lo psicológico (PAVIS, 2003, p. 50). Al abandonar el psicologismo, el/la intérprete ejecuta su trabajo de forma concreta, funcional y eficiente.

El/la espectador(a) lee las emociones del actor/actriz a través de acciones físicas. Las emociones dejan de ser para el/la intérprete algo fugaz y descontrolado, tal como ocurre en la vida real y pasan a ser "(...) posturas en movimiento, mociones físicas y mentales que le motivan en la dinámica de su juego, en el espacio-tiempo-acción de la fábula en la cual se inscribe ${ }^{5}$ (PAVIS, 2003, p. 55, traducción nuestra). En vez de dedicarse a elaboraciones introspectivas sobre sentimientos, un(a) actor/ actriz, espectador(a) o teórico(a) de la interpretación, por ejemplo, parten de la codificación de contenidos emocionales. Es más factible observar el "hacer" del actor/actriz: lo que hace de su papel, de qué manera lo crea y como se coloca con relación hacia él. En este sentido, Toporkov

LUCAS, Elisa Martins. Propuesta metodológica, principios teóricos y enfoques para el proceso de creación dramatúrgica actoral.

PÓS:Revista do Programa de Pós-graduação em Artes da EBA/UFMG. v.10, n.19: mai.2020

Disponível em < $\underline{\text { https://eba.ufmg.br/revistapos }>}$

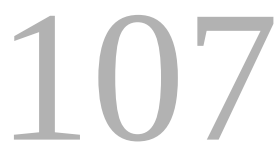


(2019, p. 54) considera como gran hallazgo de Stanislávski el hecho de trasladar la atención del actor/actriz de la indagación por la emoción interna para la ejecución de una tarea escénica, solucionando así una gran dificultad de la técnica actoral.

Las Ilamadas "posturas en movimiento" (PAVIS, 2003, p. 55) caracterizan el trabajo que el/la actor/ actriz realiza por medio de acciones físicas concretas y sencillas, ejecutadas hasta el final. El drama puede volverse físico, realizado a través del cuerpo del intérprete, por acciones realizadas en distintos momentos y espacios que absorben su consciencia. No se trata de 'querer hacer' o 'querer sentir', sino de hacerlo de forma completa con acciones claras y objetivas mediante un impulso que nace en la columna vertebral y se expande hacia el espacio.

Carreri elucida la diferencia entre acción y movimiento. Mientras que un movimiento no cambia nada en el espacio, una acción siempre cambia o quiere cambiar algo: “Esto es una acción, quiero mover mi libro - la acción siempre tiene una intención precisa. En inglés intention, 'in-tensión', tensión en el cuerpo" (CARRERI, in Traces in the Snow, 1994).

El/la intérprete puede partir de acciones que no tengan relación con el contexto del personaje, preparando previamente un listado de acciones que va a explorar físicamente en el local de ensayo y que en cierto modo se oponen a las actitudes del personaje. O puede trabajar por similitud, es decir, a partir de acciones relacionadas con el personaje. Las acciones de tirar y empujar, por ejemplo, suelen ser utilizadas en entrenamientos actorales, debido a sus características de concentración de fuerza y energía, como indica Lecoq (2003, p. 113): “La ondulación es el motor de todos los esfuerzos físicos del cuerpo humano: empujar/tirar de y empujarse/tirarse desde sí mismo".

Muchos(as) actores/actrices trabajan con acciones de base según el Análisis de Movimiento de Laban (1978), que son: apretar, rozar, golpear, flotar, torcer, doblar, azotar, deslizar, y sus variantes. Estos verbos se exploran físicamente de diversas formas: ya sea con todo el cuerpo, partiendo de una parte del cuerpo o incluso segmentando el cuerpo (la acción puede partir del pecho, del cuadril, de la cabeza, de un hombro, etc.), variando factores como velocidad (rápida o lenta),

LUCAS, Elisa Martins. Propuesta metodológica, principios teóricos y enfoques para el proceso de creación dramatúrgica actoral.

PÓS:Revista do Programa de Pós-graduação em Artes da EBA/UFMG. v.10, n.19: mai.2020

Disponível em < $\underline{\text { https://eba.ufmg.br/revistapos }>}$

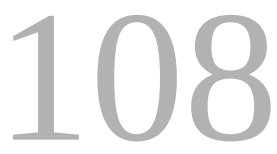


tamaño (grande o pequeño), dirección (directa o indirecta), energía (fuerte o ligera), nivel (alto o bajo), tiempo (repentino o prolongado) durante su ejecución. Aunque el Análisis de Movimiento de Laban proceda de la danza, se emplea con frecuencia en entrenamientos actorales.

Según Ferracini (2001, p. 124), cuando decodifica y codifica acciones físicas y vocales, el/la intérprete sistematiza gradualmente su trabajo y construye un vocabulario de acciones a través de lo cual puede fijar la organicidad para repetirla en el escenario y hacer que nazca en cada función los mismos impulsos accionados durante el proceso de creación. Gracias a la decodificación y repetición de movimientos, tensiones musculares, impulsos para las acciones y de todos los elementos que hacen posible una acción o conjunto de acciones, el/la intérprete memoriza y codifica su trabajo, adquiriendo así control sobre la actuación. Las emociones del personaje y el éxito de la actuación serán algo técnico: “(...) emoción para el actor/actriz, no debe ser algo abstracto y psicológico, sino, por el contrario, algo concreto y muscular, en constante movimiento, fluidez y dinámica interna"6 ${ }^{\prime F E R R A C I N I, ~ 2001, ~ p . ~ 37, ~ t r a d u c c i o ́ n ~ n u e s t r a) . ~}$

Gran material de trabajo para el/la actor/actriz, las acciones físicas pueden ser transformadas, cambiadas, reducidas o incluso suprimidas cuando se llega al escenario, desde que se mantengan sus impulsos. El/la actor/actriz puede aumentar su repertorio de acciones con distintas propuestas que enriquecerán su calidad de movimientos y ampliarán su comunicación con el público.

\subsection{El trabajo vocal: La voz también es acción en escena}

La voz nace inicialmente como un impulso corporal que se convierte en sonido, después en palabra, interfiriendo en el espacio, con infinitas posibilidades de alcanzar al espectador(a), configurándose como una herramienta más en la construcción de la ficción.

Al trabajar la voz, el/la actor/actriz amplía registros y volumen, encuentra nuevos timbres, explora los armónicos y puede, incluso, corregir anomalías. El empleo adecuado de la voz redunda directamente en el ritmo, en los diferentes tipos de dicción y en el conocimiento de las cajas de resonancia como amplificadoras del sonido, capaces de proporcionar distintos registros al intérprete. A través del trabajo vocal se intenta conseguir una voz capaz de llenar todo el espacio, sin que se pierda

LUCAS, Elisa Martins. Propuesta metodológica, principios teóricos y enfoques para el proceso de creación dramatúrgica actoral.

PÓS:Revista do Programa de Pós-graduação em Artes da EBA/UFMG. v.10, n.19: mai.2020

Disponível em < $\underline{\text { https://eba.ufmg.br/revistapos }>}$

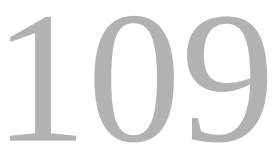


espontaneidad vocal. Cuando bien trabajada y explorada, la voz es un gran recurso actoral. Hay que poder decir un texto sabiendo dónde insertar pausas, respiraciones y suspiros, haciendo que la cadencia refleje las intenciones, con dominio técnico, aunque sin caer en tics mecánicos o rutinarios, es decir, manteniendo conexión con lo que exige cada personaje. Una narración bien expresada capta de forma inmediata la atención del espectador(a), haciendo que se adentre en el relato y lo convierta en algo suyo.

La impostación vocal, el ritmo y la forma de hablar dicen mucho de uno mismo, revelan y desnudan la personalidad, con sus experiencias y vivencias, personales, familiares y geográficas. El/la actor/ actriz que se familiariza con su propia voz puede vencer resistencias y reconocerse mejor a sí mismo(a), lo que redundará positivamente en su actuación. Es primordial que el/la intérprete desarrolle el conocimiento y la percepción corporal y emocional de su voz, para escucharse a sí mismo(a), conocer sus registros y posibilidades, y priorizar un uso óptimo de sus cuerdas vocales, sin llegar a dañarlas. Y, sobre todo, debe concienciarse de que la voz, como potencia material, es una prolongación del cuerpo, $\sin$ "(...) dualidades o subdivisiones: voz y cuerpo. Existen solamente acciones y reacciones (...)" (BARBA, 1986 p. 80) que afectarán al organismo en su totalidad.

La voz se debe apoyar en el abdomen, potencia de fuerza que permite controlar el aire con objeto de ampliar la capacidad pulmonar y lograr que el/la intérprete diga el texto en totalidad, variando el ritmo, haciendo cambios, puntualizando unas palabras más que otras y considerando factores como velocidad, dirección, energía, tiempo y volumen.

En los estudios sobre el oficio actoral hay numerosas alusiones al trabajo vocal. Pedagogos(as) teatrales, cada uno(a) con sus particularidades, según sus investigaciones, período histórico y el teatro a que se pretendían, enfatizan aspectos para tener en cuenta, indicando, incluso, propuestas de ejercicios. Stanislávski (2004) plantea la instrumentalización vocal a través de procedimientos que contribuyan al perfeccionamiento del potencial expresivo a partir del estudio de elementos como dicción, articulación, canto, entonaciones, tiempo-ritmo, colocación vocal, respiración y trabajo con el texto. Defiende que la voz del intérprete debe lograr reproducir sentimientos de los más delicados de forma objetiva y sensible, en diferentes lenguajes y propuestas estéticas. Acredita

LUCAS, Elisa Martins. Propuesta metodológica, principios teóricos y enfoques para el proceso de creación dramatúrgica actoral.

PÓS:Revista do Programa de Pós-graduação em Artes da EBA/UFMG. v.10, n.19: mai.2020 Disponível em < $\underline{\text { https://eba.ufmg.br/revistapos }>}$

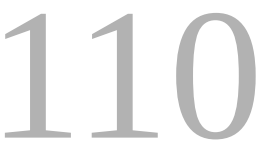


en la investigación sobre la musicalidad del lenguaje y la sensación de las palabras, proponiendo recursos como visualización de imágenes mentales, trabajo con subtexto, variaciones en la inflexión y división del texto con puntos y pausas.

Grotowski (1976) presenta un cuidado pedagógico al adoptar procedimientos adecuados al trabajo vocal en el teatro, diferentes de aquellos aplicados en cantores. Da atención especial al poder de la emisión vocal, enfatizando que la columna de aire que emite el sonido debe salir con vigor y sin obstáculos, evitando laringe cerrada o poca abertura de los maxilares. Piensa la exploración consciente e higiénica de la voz a través de la investigación individual del sistema respiratorio y del aparato fonador, destacando la investigación del sonido por cajas de resonancia como amplificadoras acústicas de la voz, siendo que la utilización del cuerpo todo como caja de resonancia es la posibilidad más productiva. Según el director polaco, la exploración vocal del actor/actriz debe resultar en entonaciones y sonidos que el/la espectador(a) no logre reproducir (Grotowski, 1976, p. 99). Por ello, defiende que, además de la labor técnica, conviene investigar en sonidos de todos tipos, incluyendo la emisión de sonidos inusuales (como la imitación de sonidos naturales, de animales y ruidos mecánicos). A partir de ese ejercicio, se puede probar con el paso de un sonido inusual al de la voz hablada, investigando semejanzas y diferencias. A este respecto, Cappa (2010, p. 13) habla de las infinitas posibilidades vocales de cada actor/actriz, que van más allá de lo que es "decir un texto o cantar", y que deben ser investigadas a través de la exploración de sonidos desconocidos, pues ellos enriquecerán el "mundo sonoro y poético" del intérprete. De la misma forma, una voz gutural, visceral, distinta del registro usual, o un grito, un llanto, un suspiro, una risa, un sofoco, un tarareo, pueden suscitar nuevas sensaciones, desconocidas y extrañas en el espectador, hasta el punto de que puede recordarle alguna situación que ha visto o vivido.

Por otra parte, Barba (2010), resalta la dimensión corporal de la voz, comprendiéndola “(...) como proceso fisiológico [que] involucra todo el organismo y le proyecta en el espacio" (BARBA, 2010, p. 81, traducción nuestra). ${ }^{7}$ Considera la voz como fuerza material que cría, direcciona, interrumpe, etc., provocando reacciones inmediatas en aquellos que son atingidos. Su trabajo tiene como objetivo incitar la imaginación vocal propria de cada actor/actriz y simultáneamente resguardar reacciones espontáneas de su voz (BARBA, 2010, p. 81).

LUCAS, Elisa Martins. Propuesta metodológica, principios teóricos y enfoques para el proceso de creación dramatúrgica actoral.

PÓS:Revista do Programa de Pós-graduação em Artes da EBA/UFMG. v.10, n.19: mai.2020

Disponível em < $\underline{\text { https://eba.ufmg.br/revistapos }>}$

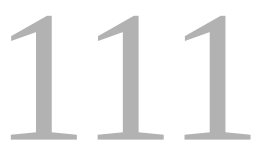


Teniendo en cuenta todo lo que aquí se indica, según su trayectoria técnico/artística, el/la actor/ actriz se prepara mediante ejercicios de respiración, articulación y proyección vocal, pasando luego a un trabajo vocal que se configura mediante imágenes, lo que incentiva potentemente su imaginación y le ayuda a emitir una voz que no parezca ni mecánica ni artificial. En ese proceso, puede imaginar/asociar verbos a su voz. Cada imagen personal ayuda el/la intérprete a encontrar su naturaleza sonora individual. Su voz puede acariciar, herir, golpear, susurrar, empujar, tranquilizar, acercar, tocar, seducir, apartar, rezar etc., tal como lo haría su cuerpo. La voz pasa a ser una reacción, una respuesta a la imagen/verbo que le sirvió de estímulo. La actriz/dramaturga ha realizado dichos ejercicios periódicamente mientras realizaba la investigación para la tesis doctoral.

Al trabajar la voz, el/la actor/actriz debe evitar el estancamiento, indagándose si respira de forma natural, es decir, de acuerdo con su propia idiosincrasia o si, por el contrario, exagera mientras actúa y, por tanto, finge que respira. El trabajo vocal de cada actor/actriz es el conjunto de sus ejercicios prácticos, a los que se suman además sus vivencias, miedos, fracasos y logros personales. El/ la intérprete debe tener una actitud de permanente descubrimiento de su voz, buscando siempre pronunciar las palabras de forma creíble.

\section{Segunda parte de la propuesta metodológica: Etapas del proceso de creación dramatúrgica actoral}

La segunda parte de la propuesta metodológica presenta las etapas para la ejecución de un proceso de creación dramatúrgica actoral, pensadas para un(a) actor/actriz que tenga un trabajo corpóreo-vocal previo tal como está propuesto en la primera parte. Se optó por organizar la metodología en etapas con el objeto de que las mismas puedan ser aprehendidas por actores y actrices contemporáneos interesados en la realización de la composición escénica conjunta a la creación textual. A lo largo de las etapas, se presentan referencias del proceso de creación que originó dicha propuesta.

LUCAS, Elisa Martins. Propuesta metodológica, principios teóricos y enfoques para el proceso de creación dramatúrgica actoral.

PÓS:Revista do Programa de Pós-graduação em Artes da EBA/UFMG. v.10, n.19: mai.2020

Disponível em $<\underline{\text { https://eba.ufmg.br/revistapos }>}$

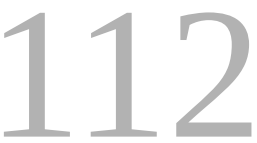




\subsection{Elección de personaje y definición del tema a ser abordado}

En esta investigación se propone un orden inverso al usado en el proceso convencional del teatro. En vez de partir de un texto dramático para construir el personaje, el/la actor/actriz puede partir de un personaje, que trabajará en el escenario, hasta construir el texto. Ese personaje, que puede tener su origen en una novela, cuento, leyenda, texto dramático o incluso en una situación real, funcionará como pretexto para lo que el/la actor/actriz/dramaturgo(a) desee comunicar a su público en la dramaturgia y, posteriormente, en el espectáculo. Por ello, el momento de la elección es fundamental.

Puede tener resultados muy positivos el trabajar con un personaje de rango secundario en una obra literaria determinada, para adoptar precisamente el punto de vista de ese personaje, convirtiéndolo en protagonista. Un ejemplo de esto es la dramaturgia brasileña Rosalina a deletada: $A$ marmelada que faltava no seu Romeu e Julieta (1998). Escrita y dirigida por Mauro Rizzo, recrea la historia de Romeo and Juliet (Shakespeare, 1594-1595) desde el punto de vista del personaje de Rosalina, sobrina de Capuleto, padre de Julieta ( $y$, por tanto, prima de la protagonista). Mencionado siete veces en la obra, el personaje no tiene ningún diálogo o acción. Al principio de la tragedia, Romeo está enamorado de Rosalina y solo va al baile (ocasión en que conocerá a Julieta) porque Benvolio le dice que ella estará allí. En Rosalina a deletada: A marmelada que faltava no seu Romeu e Julieta, Rizzo invierte el enredo de la obra como si toda la tragedia hubiera sido provocada por Rosalina, tras ser rechazada por Romeo. La acción tiene lugar en la iglesia de fray Lorenzo (personaje original del clásico, que tiene acción y diálogos), donde Rosalina confiesa al fraile sus pecados. En entrevista con la autora de este estudio, Rizzo explica el proceso empleado, que él denomina "samplear" ${ }^{\text {"s }}$ con el texto de Shakespeare y el personaje: "Cogí al fray Lorenzo 'prestado' y creé la Rosalina y su versión de la historia. (...) todo el texto de la obra son diálogos entre fray Lorenzo y Rosalina que ocurren entre las escenas del texto original". ${ }^{9}$

Tras elegir el personaje, el/la actor/actriz/dramaturgo(a) define el tema que va a explotar y como enfocará el personaje. Este proceso opera en una doble vertiente: El/la actor/actriz/dramaturgo(a) elije al personaje ' $X$ ' porque pretende abordar el tema ' $Z$ ', que va a tener relación con dicho perso-

LUCAS, Elisa Martins. Propuesta metodológica, principios teóricos y enfoques para el proceso de creación dramatúrgica actoral.

PÓS:Revista do Programa de Pós-graduação em Artes da EBA/UFMG. v.10, n.19: mai.2020 Disponível em < $\underline{\text { https://eba.ufmg.br/revistapos }>}$

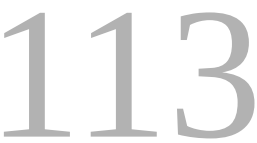


naje. O elige un personaje y se cuestiona qué temas pueden ser abordados a partir de él. También se puede hacer al revés: partir de un tema y después elegir a un personaje. Si se quiere abordar el tema de un hijo acomplejado, se puede elegir una creación dramatúrgica realizada a partir del personaje de Hamlet y no a partir de Rey Lear, por ejemplo. Por otro lado, si se pretende tratar el tema de la vejez, entonces cabría decantarse por Lear.

En la definición del tema, el/la actor/actriz necesita buscar argumentos concretos, cuestionarse sobre lo que realmente desea comunicar y por qué quiere hacerlo. Para ello, necesita investigar y tener conocimiento de su realidad y de su tiempo, buscando lo más importante y la mejor manera de compartir sus ideas con el/la espectador(a) de forma cercana, distinta y creativa. Un recurso eficaz para definir el enfoque puede ser trabajar con preguntas que funcionen como estímulo para la escritura y que puedan ser contestadas a lo largo del desarrollo de la creación dramatúrgica:

- ¿Qué determinado personaje tiene para decir?

• ¿Qué dicho personaje desearía en el tiempo presente?

- ¿Qué dicho personaje desearía en su tiempo (cuando se tratar de una figura histórica)?

En la búsqueda del tema puede ayudar materiales de procedencia diversa: noticias de periódicos, leyendas, situaciones, propuestas temáticas, suposiciones, poemas, ideas lúdicas y todo aquello que contribuya como estímulo a la imaginación del actor/actriz/dramaturgo(a).

Para el experimento de la investigación doctoral se eligió al personaje bíblico- literario-legendario de María Magdalena porque dicha figura "(...) a lo largo de los siglos, adquirió gran importancia en el imaginario popular cristiano occidental a partir de leyendas y tradiciones relacionadas con su nombre" (LUCAS, 2019, p. 157), convirtiéndose en un personaje que podría ser representado desde ángulos diversos en una creación de ficción. El tema abordado fue la trayectoria del personaje, enfocando a un tiempo sus aspectos sacro y profano bajo la perspectiva indicada por Eliade (1998, p. 17): “(...) lo sagrado y lo profano constituyen dos modalidades de estar en el mundo, dos situaci-

LUCAS, Elisa Martins. Propuesta metodológica, principios teóricos y enfoques para el proceso de creación dramatúrgica actoral.

PÓS:Revista do Programa de Pós-graduação em Artes da EBA/UFMG. v.10, n.19: mai.2020

Disponível em < $\underline{\text { https://eba.ufmg.br/revistapos }>}$

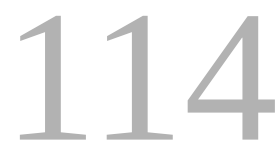


ones existenciales asumidas por el hombre a lo largo de su historia". A los dos aspectos "(...) se les concedieron un tratamiento puramente escénico, sin aspirar a posicionamientos filosóficos o teológicos de ningún tipo" (LUCAS, 2019, p. 157).

\subsection{Estudio del personaje en diversas fuentes}

Tras la elección de personaje y definición del tema, el/la actor/actriz/dramaturgo(a) empieza a estudiar el personaje en todas las fuentes disponibles, mediante una investigación que le permita configurar una imagen lo más completa posible del mismo. Se seleccionan desde bibliografías que servirán para el conocimiento del personaje abordado (ensayos, cuentos, novelas, poemas, incluyendo recreaciones literarias hechas a partir de dicho personaje), hasta recursos expresivos (referencias fílmicas, fotográficas, musicales, pictóricas, etc.), así como situaciones y experiencias de vida que puedan tener alguna relación con el personaje. A veces, determinado material puede no estar directamente relacionado con el personaje o con el tema que se va a abordar, pero, por su lenguaje o por sus temas, podrá contribuir a la creación.

Siguiendo tales pasos, la autora consultó fuentes bibliográficas, folclóricas y pictóricas, procedentes de diferentes tradiciones en una investigación que incluyó trabajo de campo en la Semana Santa de Sevilla y visita y registro fotográfico a la Parroise de la Madeleine (Paris) (LUCAS, 2019, p.157).

\subsection{Elección de situaciones, definición de objetivos del personaje y recogida de estímulos para la creación}

Tras el estudio de todo el material, el/la actor/actriz selecciona las situaciones del personaje que llevará a la escena según el tema que pretenda enfocar. Elabora un listado con las situaciones y apuntes de lo que considera más importante a la hora de enfocar en la dramaturgia. A partir de las situaciones, define posibles objetivos que el personaje pretenderá alcanzar a lo largo de la obra e igualmente los registra en otro listado. El/la actor/actriz puede ejecutar esta etapa solo(a) o en colaboración con un(a) director(a), cuando lo haya. En el caso del proceso que originó esta propuesta metodológica, a través del estudio de María Magdalena fueron listadas situaciones originarias de

LUCAS, Elisa Martins. Propuesta metodológica, principios teóricos y enfoques para el proceso de creación dramatúrgica actoral.

PÓS:Revista do Programa de Pós-graduação em Artes da EBA/UFMG. v.10, n.19: mai.2020

Disponível em < $\underline{\text { https://eba.ufmg.br/revistapos }>}$

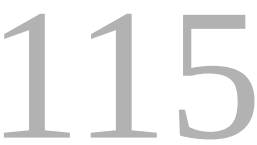


las tradiciones evangélica, eclesiástica, legendaria y pictórica (LUCAS, 2019). A partir del listado se seleccionaron "(...) situaciones en las cuales se podría enfocar aspectos profanos o sacros con relación al personaje" (LUCAS, 2019, p. 160).

En lo que concierne a los posibles objetivos que María Magdalena pretendería lograr a lo largo de la obra, la autora listó los siguientes: a) Confesarse; b) Contar su historia: su hambre, sus ansias y su soledad; c) Salir de la Torre de Magdala en donde está presa desde la infancia por tener visiones y posesiones; d) Saciar su hambre; e) Obtener la curación de sus posesiones; f) Entregarse al placer de los cuerpos; g) Obtener conocimiento; h) Salvar a Cristo; i) Huir con Cristo; j) Anunciar la doctrina de Jesucristo y ser escuchada (LUCAS, 2019, p. 162-163).

A continuación, el/la actor/actriz se dedica a recoger estímulos para la creación, como por ejemplo materiales escénicos que tengan relación con el personaje o con el tema enfocado, tales como: pinturas, objetos, telas, elementos de vestuario, un elemento escenográfico (escalera, silla, maleta, etc.), melodías que puedan ayudar a definir las atmósferas del personaje en distintos momentos, o incluso un estímulo sonoro, acciones físicas y vocales relacionadas con el personaje, etc. Estos materiales servirán de estímulo durante las experimentaciones y después podrán ser sugeridos en la dramaturgia con el fin de promover la interacción del texto con ellos. No es necesario que sean materiales nuevos, pues serán manipulados de diversas formas en las experimentaciones.

Puede ocurrir que determinado objeto ayude al actor/actriz a crear una escena, pero en el momento del montaje de la obra sea reemplazado por otro, o incluso suprimido. También puede ocurrir que un objeto funcione tan bien que acompañe al actor/actriz durante la creación dramatúrgica hasta la puesta en escena. No hace falta reunir muchos objetos. Se puede hacer un listado de objetos que parezcan interesantes, y que poco a poco serán incorporados en las experimentaciones. Igualmente, de acuerdo con la evolución del trabajo y con la necesidad, se pueden ir adquiriendo otros materiales. Puede ocurrir que el/la actor/actriz haga un listado de cinco objetos y ninguno de ellos funcione escénicamente, por lo que tendrá que seguir probando.

LUCAS, Elisa Martins. Propuesta metodológica, principios teóricos y enfoques para el proceso de creación dramatúrgica actoral.

PÓS:Revista do Programa de Pós-graduação em Artes da EBA/UFMG. v.10, n.19: mai.2020 Disponível em < $\underline{\text { https://eba.ufmg.br/revistapos }>}$

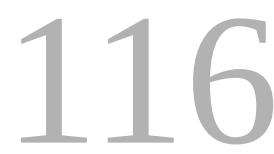


Los materiales recogidos para la investigación doctoral incluyeron músicas ejecutadas en la Semana Santa de Sevilla y de las culturas árabe y egipcia. También fueron utilizados jarros y perfumes (en alusión a uno de los atributos del personaje), inciensos, hojas representando a papiros, velas, telas, arena, hierba seca representado a mirra, y comida (LUCAS, 2019, p. 163).

\subsection{Experimentaciones a través de improvisaciones corpóreo-vocales, producción de material textual y posibles asociaciones}

Con las situaciones elegidas, los objetivos que el personaje deseará alcanzar a lo largo de la obra, los apuntes de lo que considera significativo para la dramaturgia y los materiales escénicos seleccionados, el/la actor/actriz empieza las experimentaciones a través de improvisaciones corpóreovocales. Por medio de ellas investigará en la escena cada una de las situaciones con el fin de descubrir las que más le aportan en cuanto a posibilidades dramatúrgicas y escénicas, y las que menos funcionan.

El/la actor/actriz empieza su entrenamiento, seguido del trabajo con las acciones físicas y el trabajo vocal (ya relacionándoles con el personaje y el enfoque dado), pasando a continuación a realizar improvisaciones corpóreo-vocales con cada una de las situaciones elegidas y los materiales seleccionados. Las improvisaciones deben ser realizadas con elementos que puedan perfeccionar la actuación mientras el/la intérprete experimenta posibilidades dramatúrgicas: la respiración, el peso, los sonidos, los impulsos corporales y consecuentemente las acciones y reacciones que pueda tener el personaje según su carácter y las situaciones elegidas.

El/la actor/actriz debe estar involucrado interiormente con la improvisación. No se trata de estar en el mundo de las ideas, pero todo lo que hace externamente durante la improvisación debe tener una motivación interna. Igualmente, todo debe ser resuelto, decidido y ejecutado en el escenario, sin pensamientos previos. El/la intérprete se sirve de todas sus herramientas para corporeizar las situaciones de la vida del personaje y de la historia que pretenda contar. Para ello, en el desarrollo de las improvisaciones, debe estar atento para explorar variaciones, cambios de ritmo y asociaciones sonoras y visuales.

LUCAS, Elisa Martins. Propuesta metodológica, principios teóricos y enfoques para el proceso de creación dramatúrgica actoral.

PÓS:Revista do Programa de Pós-graduação em Artes da EBA/UFMG. v.10, n.19: mai.2020

Disponível em < $\underline{\text { https://eba.ufmg.br/revistapos }>}$

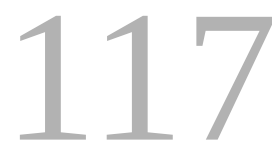


En esta fase del proceso la improvisación se configura como un recurso eficiente debido a los límites y reglas objetivas que dejan el imaginario del actor/actriz libre para la creación. Si la improvisación puede parecer a veces sencilla, en algunos procedimientos es un ejercicio difícil por exigir objetividad de acciones y economía de movimientos. Una improvisación debe comunicar con el/la espectador(a) y tener normas objetivas. No se debe plantear nada complicado. Para Spolin (2003) el/la actor/actriz, durante una improvisación debe mostrar: 1) El lugar donde ocurre la escena; 2) El tipo de acción que se muestra, y 3) Quién la ejecuta. El/la actor/actriz también tiene la posibilidad de utilizar metáforas e imágenes relacionadas con el personaje que puedan ser traducidas en movimientos, sonidos o poses corporales en improvisaciones más abstractas que podrán dar un carácter poético al trabajo.

A continuación, el/la actor/actriz/dramaturgo(a) pasa a incorporar lentamente los materiales escénicos seleccionados, otorgándoles distintas funciones. Las melodías seleccionadas también pueden servir de estímulo en las improvisaciones, ya que para el espectáculo y el ego de los personajes la música en la escena puede adquirir función integradora o desintegradora (PAVIS, 2003, p. 133). A cada improvisación son producidos materiales textuales, que serán elaborados con estructura de texto dramatúrgico.

Durante las improvisaciones, el/la actor/actriz debe permitir que surjan asociaciones inesperadas que posibilitarán la creación de nuevas situaciones relacionadas con el personaje o con el tema tratado. Un gesto ejecutado puede remitir a una situación leída anteriormente. Una situación puede proponer un sonido, este sonido puede desencadenar en un estado corporal, y así sucesivamente. Dichas asociaciones podrán resultar en nuevas propuestas de improvisaciones, nuevos elementos textuales y nuevos objetivos que no habían sido inicialmente planteados, pero que se fueron descubriendo a partir del trabajo práctico.

El/la actor/actriz también debe tener en cuenta que está construyendo una historia que más tarde será compartida con el público. Para ello, debe buscar formas de introducir al espectador(a) en la ficción, haciendo que la creación dramatúrgica proporcione a los(as) asistentes su participación, para tomar parte en la vida del personaje, como si fuera la suya también. Es decir, hay que lograr

LUCAS, Elisa Martins. Propuesta metodológica, principios teóricos y enfoques para el proceso de creación dramatúrgica actoral.

PÓS:Revista do Programa de Pós-graduação em Artes da EBA/UFMG. v.10, n.19: mai.2020 Disponível em < https://eba.ufmg.br/revistapos $>$

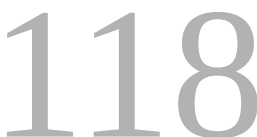


construir un texto que, cuando sea llevado a escena, comunique con el/la espectador(a), haciendo que el público salga del teatro habiendo comprendido una historia (con desarrollo evolutivo o fragmentado) y reconociéndose en ella.

En dicha etapa del proceso que originó esa propuesta, la autora buscó ejecutar acciones físicas y vocales completas, investigando distintas atmósferas, intentando transcenderlas sin perder la coherencia, dejando su imaginario libre para crear asociaciones inesperadas que contribuyesen a la creación de textos/escenas y buscando sorprenderse a sí misma con reacciones espontáneas (LUCAS, 2019, p. 163). Las improvisaciones realizadas incluyeron, entre otros aspectos, el ansia incontrolable, la gula, el deseo sexual y el hambre de conocimiento de María Magdalena, el sexo como algo profano y prohibido y las supuestas orgías de una persona poseída. Estas improvisaciones sirvieron de base para crear el siguiente texto:

En la Torre de Magdala, cuando la poseída se convierte en meretriz y cambia placeres por conocimiento, todas las almas se encuentran y los cuerpos resplandecen. La ley suprema es el éxtasis que derrite cuerpos en sudor, perfumes y olor de esperma. Los arcángeles se inclinan con la sonrisa de las miradas maliciosas. Y las vírgenes se entregan en el sacrificio del propio placer (LUCAS, 2011, p. 9).

La inserción del espectador(a) en la ficción se dio a través de la creación de una coreografía ejecutada con una tela que estilizaba y sugería movimientos de una relación sexual (LUCAS, 2019, p. 164). En dicha coreografía, que aparece en las acotaciones del texto, María Magdalena camina hacia los espectadores, insinuándose, "(...) en una especie de celebración del propio cuerpo" (LUCAS, 2011 , p. 9). La opción por utilizar el recurso de una narradora, también se dio con objeto de introducir el espectador en la ficción, una vez que la narradora presentaría la trayectoria de María Magdalena, intermediándola con los espectadores.

LUCAS, Elisa Martins. Propuesta metodológica, principios teóricos y enfoques para el proceso de creación dramatúrgica actoral.

PÓS:Revista do Programa de Pós-graduação em Artes da EBA/UFMG. v.10, n.19: mai.2020 Disponível em < $\underline{\text { https://eba.ufmg.br/revistapos }>}$

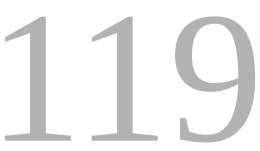




\subsection{Organización y encadenamiento de escenas creadas a partir de las improvisaciones}

Cuando ya se tiene una cantidad considerable de material textual, se empieza a compaginar el trabajo práctico con el trabajo de mesa, y se ordena las escenas creadas a partir de las improvisaciones, comparándolas con las situaciones elegidas y con los objetivos inicialmente planteados para el personaje. Después viene el trabajo de transformar dichas improvisaciones en escenas con principio, medio y final y luego, el intento de encadenarlas, llegando a formar una narración que tenga estructura dramática. En el transcurso del trabajo, las escenas se seleccionan, se mejoran, se decodifican, se repiten y luego se codifican, a fin de que tengan fluidez.

\subsection{Primer esbozo de guion, descarte y añadidura de situaciones y materiales}

Con el fin de trazar un primer esbozo de guion, el/la actor/actriz/dramaturgo(a) reúne las escenas creadas con un desarrollo evolutivo, considerando el material estudiado, las prácticas realizadas y una correlación dramática entre las acciones y soluciones escénicas trabajadas en las experimentaciones. Estas soluciones podrán ser sugeridas en las acotaciones del texto, a modo de indicaciones de acción, escenografía, coreografía, etc.

A continuación, las situaciones y materiales que no funcionaron escénicamente o que no proporcionaron materiales dramatúrgicos significativos son descartadas. Por ejemplo: una situación " $\mathrm{X}$ " puede devenir en un bello texto literario, pero no funciona en el escenario como parlamento, por lo que debe ser eliminada. De la misma forma, son añadidas las nuevas situaciones, escenas, textos y objetivos surgidos a partir de las improvisaciones y sus asociaciones. Es como si todo el trabajo teórico-práctico realizado hasta aquí funcionase como un activador/estimulador de la imaginación del actor/actriz para escribir con todo su psicofísico de forma intensa e involucrada, a partir de estudios, materiales y experimentaciones realizadas en torno al personaje y al tema tratado.

LUCAS, Elisa Martins. Propuesta metodológica, principios teóricos y enfoques para el proceso de creación dramatúrgica actoral.

PÓS:Revista do Programa de Pós-graduação em Artes da EBA/UFMG. v.10, n.19: mai.2020

Disponível em < $\underline{\text { https://eba.ufmg.br/revistapos }>}$

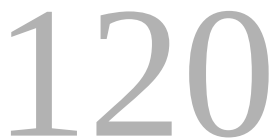




\subsection{Definiciones objetivas, ficcionalización de lagunas y finalización del texto}

Sobre la base del primer esbozo, se hacen definiciones objetivas que no se descubrieron a través del trabajo realizado hasta entonces, como por ejemplo elección del título de la obra, personajes que irán a figurar y personajes que serán eliminados, etc. Entonces, el/la actor/actriz/dramaturgo(a) diseña un esquema dramatúrgico con inicio, desarrollo y final, y con los principales objetivos del personaje en cada momento.

Es normal que el primer esbozo presente lagunas que deberán ser cubiertas a base de nuevos textos que podrán ser creados de forma objetiva en un trabajo de mesa, según el esquema dramatúrgico y los objetivos del personaje. Realizada esta complementación con el trabajo de mesa, el texto es finalizado y el/la actor/actriz pasará al trabajo de planteamiento y preparación de la puesta en escena, hasta estrenar el texto creado.

El esbozo de guion diseñado en el proceso ejecutado presentaba poéticamente la trayectoria de María Magdalena en formato de un monólogo. Se seleccionaron los personajes que figurarían en la obra aparte de la protagonista. El título elegido, La Dama de los Evangelios, hace alusión al origen literario del personaje, al mismo tiempo que sugiere su otro aspecto, ya que tanto la tradición eclesial como algunas leyendas insinúan que María Magdalena fue prostituta, de ahí que el título indica también su estigma, presentándola como "dama" que, en cierta medida, se asemeja a "madama".

La autora creó una línea cronológica ficticia de la vida de la protagonista indicando los sucesos más emblemáticos de su trayectoria y sus respectivos objetivos, que "(...) funcionó como un condensado actancial que contenía los núcleos generadores de los conflictos dramáticos relacionados con el personaje y, consecuentemente, con su acción dramática" (LUCAS, 2019, p. 169-170).

LUCAS, Elisa Martins. Propuesta metodológica, principios teóricos y enfoques para el proceso de creación dramatúrgica actoral.

PÓS:Revista do Programa de Pós-graduação em Artes da EBA/UFMG. v.10, n.19: mai.2020

Disponível em < $\underline{\text { https://eba.ufmg.br/revistapos }>}$

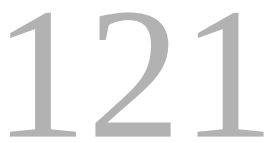


Durante la fase de ficcionalización, el guion fue alterado a través de cortes, separación de los textos dichos en primera persona (María Magdalena) de los narrados en tercera persona (Narradora). Buscando enriquecer la historia de la protagonista, se cambiaron algunos textos y se perfilaron otros. Igualmente, se crearon nuevas escenas basándose en tradiciones, narrativas legendarias y ficticias con respecto al personaje.

El texto final de La Dama de los Evangelios, publicado en Dramaturgia de Iberescena: Antología (México, 2012), presenta un lenguaje poético e intimista, expresándose en tercera y primera persona: Una Narradora que conta la historia de María Magdalena y María Magdalena que reacciona y confesa su propia historia.

\section{Conclusiones}

La propuesta metodológica para el proceso de creación dramatúrgica actoral presentada en este artículo se muestra como opción a la teoría y práctica teatral. Para desarrollarla, el/la actor/actriz/ dramaturgo(a) debe desenvolver una serie de etapas, explorar técnicas apropiadas (entrenamiento actoral, trabajo con las acciones y la voz e improvisación teatral), optar por un personaje atractivo como para comunicarse con el público, tener claro su enfoque y apoyarse en una investigación consistente.

En un momento histórico en que el/la actor/actriz toma las riendas de su creación, tanto en el ámbito textual como de escenificación, dicha propuesta ofrece caminos al ejercicio de la creación dramatúrgica a partir de la instrumentalización del cuerpo/voz del intérprete, del ejercicio de la improvisación y de la experimentación con distintos estímulos. Incorpora a la labor actoral elementos autorales (autoría textual), posibilitando que el/la actor/actriz/dramaturgo(a) trabaje a partir de sus elecciones - poéticas, estéticas e ideológicas - y ofreciéndole una visión más amplia de su trabajo.

LUCAS, Elisa Martins. Propuesta metodológica, principios teóricos y enfoques para el proceso de creación dramatúrgica actoral.

PÓS:Revista do Programa de Pós-graduação em Artes da EBA/UFMG. v.10, n.19: mai.2020

Disponível em < $\underline{\text { https://eba.ufmg.br/revistapos }}>$

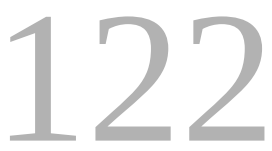


Dicha propuesta puede ser una herramienta para actores y actrices que deseen crear sus proprias dramaturgias a través de la unión de la creación textual a la composición escénica. De la misma forma, puede contribuir en la formación de alumnos(as) de Artes Escénicas (principalmente los de actuación y dramaturgia, pero también lo(a)s de dirección), proporcionándoles instrumentalización para dar voz a sus creaciones y autonomía en sus procesos. La sistematización abre oportunidad para futuras investigaciones acerca de la experimentación por parte de otros(as) actores/actrices/ dramaturgos(as) con objeto de evaluar la potencialidad, eficacia y deficiencias de la metodología y así permitir ajustarla a las necesidades de diferentes intérpretes. Además, se pretende en futuras investigaciones aplicar dicha metodología en otros(as) actores/actrices, con objeto de testar su eficacia y perfeccionar sus posibles debilidades.

LUCAS, Elisa Martins. Propuesta metodológica, principios teóricos y enfoques para el proceso de creación dramatúrgica actoral.

PÓS:Revista do Programa de Pós-graduação em Artes da EBA/UFMG. v.10, n.19: mai.2020 Disponível em < $\underline{\text { https://eba.ufmg.br/revistapos }}>$ 


\section{REFERENCIAS}

BARBA, Eugenio. Más allá de las islas flotantes. México: Grupo Editorial Gaceta, 1986. (Colección Escenología)

BARBA, Eugenio. Teatro: Solidão, Ofício, Revolta. Tradução de Patrícia Furtado de Mendonça. Brasília: Teatro Caleidoscópio, 2010.

BORGDORFF, Henk. El debate sobre la investigación en las artes. Cairon: Revista de Ciencias de la Danza, Alcalá de Henares: Servicio de Publicaciones de la Universidad de Alcalá, n. 13, p. 25-46, 2010.

CAPPA, Natalia. La voz en escena. SAVERIO: Revista cruel de teatro, año 4, n. 13, p. 12-14, mar. 2010.

CARRERI, Roberta. El viaje del actor, del training al espectáculo. Revista Máscara, Cuaderno Iberoamericano de Escenología, año 2, n. 9-10, abr.-jul. 1990.

ELIADE, Mircea. Lo Sagrado y lo Profano. Traducción de Luis Gil Fernandez y Ramón Alfonso Díez Aragón. Barcelona: Paidós Orientalia, 1998.

FERRACINI, Renato. A arte de não interpretar como poesia corpórea do ator. Campinas: Editora da Unicamp, 2001.

GROTOWSKI, Jerzy. Em busca de um teatro pobre. Tradução de Aldomar Conrado. 2. ed. Rio de Janeiro: Civilização Brasileira, 1976.

LABAN, Rudolf. Domínio do Movimento: Organização de Lisa Ullmann. Tradução de Anna Maria Barros de Vecchi e Maria Sílvia Mourão Netto. 5. ed. São Paulo: Summus, 1978.

LECOQ, Jacques. El Cuerpo Poético: Una pedagogía de la creación teatral. Traducción y adaptación al español: Joaquín Hinojosa y María del Mar Navarro. Barcelona: Alba Editorial 2003.

LECOQ, Jacques (Org.). Le Théâtre du Geste: mimes et acteurs. Paris: Bordas Spectacles, 1987.

LUCAS, Elisa Martins. Lo Profano y lo Sagrado en el proceso de creación dramatúrgica del actor a partir del personaje de María Magdalena. Interrelación entre teoría y praxis escénica. 2015. Tesis (Doctorado en Ciencias del Espectáculo) - Programa de Doctorado en Ciencias del Espectáculo, Facultad de Filología, Universidad de Sevilla, Sevilla, 2016.

LUCAS, Elisa Martins. Relatos del proceso de creación del texto La Dama de los Evangelios. Sevilla/Porto Alegre, 2011. 21 f. Inédito.

LUCAS, Elisa Martins. Un experimento de proceso de creación dramatúrgica del actor a partir del personaje de María Magdalena. DAPesquisa, Florianópolis, v. 14, p. 155-175, 2019. Consultado el

LUCAS, Elisa Martins. Propuesta metodológica, principios teóricos y enfoques para el proceso de creación dramatúrgica actoral.

PÓS:Revista do Programa de Pós-graduação em Artes da EBA/UFMG. v.10, n.19: mai.2020

Disponível em < $\underline{\text { https://eba.ufmg.br/revistapos }>}$

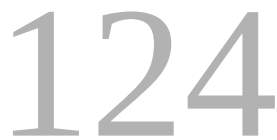


27 de enero de 2020. Disponible en:

<http://www.revistas.udesc.br/index.php/dapesquisa/article/view/1808312914232019155>

MAROCCO, Ines et al. Técnicas Corporais do Gaúcho e sua relação com a performance do Ator/Dançarino. In: XIV SALÃO E XI FEIRA DE INICIAÇÃO CIENTÍFICA DA UFRGS, 2002, Porto Alegre.

Livro de Resumos Iniciação Científica 2002, Porto Alegre: UFRGS, 2002. p. 903.

OIDA, Yoshi. O Ator Invisível. Tradução de Marcelo Gomes. São Paulo: Beca Produções Culturais, 2001.

PAVIS, Patrice. A Análise dos Espetáculos. Traduzido por Sérgio Sálvia Coelho. São Paulo: Perspectiva, 2003.

PÉREZ, Victória Royo; SÁNCHEZ, José Antonio Martínez. La Investigación en Artes Escénicas: introducción. Cairon: Revista de Ciencias de la Danza, Alcalá de Henares: Servicio de Publicaciones de la Universidad de Alcalá, n. 13, p. 5-14, 2010.

SÁNCHEZ, José Antonio. Investigación y Experiencia. Metodologías de la Investigación Creativa en Artes Escénicas. Estudis Escènics. Quaderns de I'Institut del Teatre, Barcelona: Diputació Barcelona, n 35, p. 327 -335, 2009. Consultado el 29 de marzo de 2019. Disponible en: $<$ http://www.raco.cat/index.php/EstudisEscenics/article/view/252850>.

SPOLIN, Viola. Improvisação para o Teatro. Tradução e revisão de Ingrid Dormien Koudela e Eduardo José de Almeida Amos. 4. ed. reimp. São Paulo: Perspectiva, 2003.

STANISLÁVSKI, Constantin. A construção da personagem. Tradução de Pontes de Paula Lima. 12. ed. Rio de Janeiro: Civilização Brasileira, 2004.

TOPORKOV, Vassíli. Stanislávski ensaia: memórias. Tradução e notas de Diego Moschkovich. São Paulo: É Realizações, 2016.

TRACES in the Snow. Director: Torgeir Wethal Co-producción entre Odin Teatret y Documento Films (Atenas). Con el apoyo de Kulturfonden 99 min. En inglés, subtítulos en danés, español, francés e italiano. 1994. DVD.

LUCAS, Elisa Martins. Propuesta metodológica, principios teóricos y enfoques para el proceso de creación dramatúrgica actoral.

PÓS:Revista do Programa de Pós-graduação em Artes da EBA/UFMG. v.10, n.19: mai.2020

Disponível em < $\underline{\text { https://eba.ufmg.br/revistapos }>}$

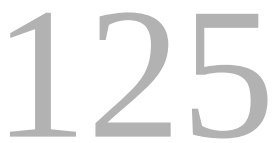




\section{NOTAS}

1 Por una cuestión feminista, en este artículo se optó por escribir actor/actriz y no solamente actor (sustantivo en el masculino).

2 La autora ha realizado la 12a Edición de esta residencia (2019) en Brasilia, Brasil.

3 La autora ha realizado dos ediciones de este taller (2011 y 2013) en Porto Alegre, Brasil.

4 Investigación en vigor en el Departamento de Arte Dramático de la Universidade Federal do Rio Grande do Sul (UFRGS), Brasil, desde el año de 2001.

5 “(...) posturas em movimento, moções físicas e mentais que o motivam na dinâmica de seu jogo, o espaço-tempo-ação da fábula na qual se inscreve".

6 "(...) emoção para o ator, não deve ser algo abstrato e psicológico, mas, ao contrário, algo concreto e muscular, em constante movimento, fluidez e dinâmica interna".

7 “(...) como processo fisiológico [que] envolve todo o organismo e o projeta no espaço"

8 Verbo del idioma portugués que es una adaptación del verbo inglés sample. Es cuando un pinchadiscos coge "prestado" una muestra de una música para usar o citar en sus mezclas.

9 Entrevista personal con la autora realizada el 16 de septiembre de 2015. 